\title{
Analisis Perilaku Spiritual Terhadap Penerapan Spritual pada Pasien Gangguan Jiwa di Rumah Sakit Jiwa Banda Aceh
}

\author{
Analysis of Spiritual Behavior on Spritual Application in Patiens of Life \\ Disorders in Banda Aceh Hospital
}

\author{
Kasihani $^{1}$, Syarifuddin ${ }^{* 2}$ \\ ${ }^{1}$ Program Studi Ilmu Keperawatan, Fak. Kedokteran, Universitas Abulyatama, Jln. Blang Bintang Lama, Km. 8,3. Aceh \\ Besar, 23373, Indonesia \\ ${ }^{2}$ Program Studi Agribisnis, Fak. Pertanian, Universitas Abulyatama, Jln. Blang Bintang Lama, Km. 8,3, Aceh Besar, 23373 , \\ Indonesia \\ *Korespondensi Penulis : Syarifuddinhasan767@gemail.com
}

\begin{abstract}
Abstrak
Spiritualitas merupakan suatu kekuatan yang dibutuhkan pasien selama di rawat di rumah sakit. Spiritualitas dapat mempengaruhi proses penyembuhan dan penguatan diri atau dalam menghadapi penyakitnya. Pendekatan sistematis terhadap perawatan spiritual pasien menjamin perawatan yang tepat dan efektif. Perilaku manusia mencakup tiga komponen, yaitu pengetahuan, sikap atau mental dan tingkah laku. Sikap atau mental merupakan sesuatu yang melekat pada diri manusia. Mental diartikan sebagai reaksi manusia terhadap sesuatu keadaan atau peristiwa, sedangkan tingkah laku merupakan perbuatan tertentu dari manusia sebagai reaksi terhadap keadaan atau situasi yang dihadapi. Perbuatan tertentu ini dapat bersifat positif dapat pula negatif. Tujuan penelitian yaitu untuk menganalisis perilaku spiritualitas terhadap penerapan spiritualitas pada pasien gangguan jiwa di Rumah Sakit Jiwa Pemerintah Aceh. Desain dalam penelitian deskriptif korelasional dengan pendekatan cross sectional study. Populasi berjumlah 41 orang dengan pengambilan sampel menggunakan teknik total sampling. Waktu penelitian dilakukan pada tanggal 04-07 Desember 2018. Hasil penelitian menunjukkan terdapat hubungan pengetahuan spritualitas terhadap penerapan spritualitas pada pasien dengan nlai p-Value $(0,03)$ tidak terdapat hubungan sikap spritualitas pasien dengan penerapan spritualitas dengan nilai p-Value $(0,22)$, terdapat hubungan tindakan spritualitas pasien dengan penerapan spritulitas dengan nilai p-Value $(0,02)$. Diharapkan kepada perawat untuk meningkatkan pengetahuan pasien jiwa untuk mengubah perilaku, penerapan spritualitas pada pasien sehingga pasien mendapatkan spritulitas yang dapat mengembalikan semangat untuk kesembuhan.
\end{abstract}

Kata Kunci: Perilaku Spritualitas, Pasien Gangguan Jiwa

\begin{abstract}
Spirituality is a strength that is needed by patients while being treated in a hospital. Spirituality can affect the healing and strengthening of oneself or in the face of illness. A systematic approach to the patient's spiritual care ensures proper and effective treatment. Human behavior includes three components, namely knowledge, attitude or mental and behavior. Attitude or mentality is something inherent in human beings. Mental is interpreted as a human reaction to a situation or event, while behavior is a particular act of humans in
\end{abstract}


reaction to the situation or situation at hand. This particular action can be positive or negative. The purpose of the study was to analyze the spirituality behavior of the application of spirituality in people with a mental disorder in the Aceh Government Mental Hospital. The design in the study was descriptive correlational with a cross-sectional study approach. The population is 41 people with sampling using the total sampling technique. The time of the study was carried out on December 4 to 2018. The results of the study showed that there was a relationship between spiritual knowledge on the application of spirituality in patients with a p-Value (0.03); no relationship between the patient's spiritual attitude and the application of spirituality with p-Value $(0,22)$; and there is a relationship between the patient's spiritual actions and the application of spirituality with the value $R$, Value (0.02). It is expected that nurses can increase the knowledge of patients with a mental health condition to change behavior, apply spirituality to patients so that patients get a spirituality that can restore enthusiasm for their recovery.

Keywords: Spirituality Behavior, Mental Disorder

\section{PENDAHULUAN}

Kesehatan merupakan kebutuhan dasar setiap manusia dan merupakan modal setiap warga Negara dan setiap bangsa dalam mencapai tujuannya dan mencapai kemakmuran. Pembangunan kesehatan pada hakekatnya adalah upaya yang dilaksanakan oleh semua komponen Bangsa Indonesia yang bertujuan untuk meningkatkan kesadaran, kemauan, dan kemampuan hidup sehat bagi setiap orang agar terwujud derajat kesehatan masyarakat (Depkes, R.I, 2009).

Dimensi sehat pada manusia itu meliputi dimensi biologis (fisik), psikologis, sosial, kultural dan spiritual.Kebutuhan spiritual merupakan kebutuhan dasar yang dibutuhkan oleh setiap manusia. Apabila seseorang dalam keadaan sakit, maka hubungan dengan Tuhannya pun semakin dekat, mengingat seorang dalam kondisi sakit menjadi lemah dalam segala hal, tidak ada yang mampu membangkitkannya dari kesembuhan kecuali Sang Pencipta. Kebutuhan spiritual mempertahankan atau mengembalikan keyakinan, memenuhi kewajiban agama (Ilhamsyah, 2010).

Pengaruh kekuatan spiritualitas tidak hanya berpengaruh pada saat sakit, namun juga berpengaruh pada kesuksesan, kinerja, dan kualitas hidup manusia. Spiritualitas terbukti mampu membawa manusia menuju kesuksesan dan menjadikan seseorang menjadi powerful leader. Pemenuhan kebutuhan spiritualitas adalah hal yang tidak bisa diabaikan. Kebutuhan spiritualitas telah terbukti dapat memberikan kekuatan pada pasien saat menghadapi penyakitnya (Hamid, A. Yani, 2014). 
Kebutuhan spiritual sebagai bagian dari kebutuhan manusia secara utuh tidak terkecuali pada pasien gangguan jiwa. Pemenuhan kebutuhan spiritual diperlukan oleh pasien dan keluarga dalam mencari arti kehidupan yang dihadapi termasuk penderitaan karena sakit dan merasa tetap dicintai oleh sesama manusia dan Tuhan (Hamid, A. Yani, 2014).

Mengacu pada peran perawat sebagai pemberi asuhan keperawatan yang komprehensif meliputi bio-psiko-sosio-spiritual maka pelaksanaan pemberian bimbingan spiritual pada pasien dengan kondisi sakit teramatlah penting. Mengingat kondisi sakit dapat mengakibatkan pasien mengalami distress spiritual, sementara kegiatan spiritual seperti berdo'a terbukti mampu menenangkan klien dalam menghadapi kenyataan tentang penyakitnya. Kondisi distress spiritual pada penderita penyakit baik akut maupun terminal jutsru akan mempersulit kondisi sakitnya, karena kebanyakan penderita tersebut akan merasa frustasi dan menyerah pada kondisinya sehingga terapi yang diperoleh dari luar seperti obat-obatan tak mampu menyembuhkan oleh karena itu keyakinan dan kepercayaan sangat mempengaruhi keberhasilan penatalaksanaan penyakit. Masalah dalam penelitian ini yaitu bagaimana hubungan perilaku spiritualitas terhadap penerapan spiritualitas pada pasien gangguan jiwa pada Rumah Sakit Jiwa Pemerintah Aceh Tahun 2018.

Berdasarkan latar belakang permasalahan yang telah dikemukakan maka penulis tertarik untuk melakukan penelitian dengan judul "Analisis perbandingan perilaku spiritualitas terhadap penerapan spiritualitas pada pasien gangguan jiwa pada Rumah Sakit Jiwa Pemerintah Aceh Tahun 2018”. Tujuan penelitian ini adalah untuk menegetahui hubungan perilaku spiritualitas terhadap penerapan spiritualitas pada pasien gangguan jiwa pada Rumah Sakit Jiwa Pemerintah Aceh Tahun 2018.

\section{METODE PENELITIAN}

Penelitian ini adalah desain deskriptif korelasional. Pendekatan penelitian menggunakan cross sectional, Penelitian ini dilaksanakan pada Rawat Inap Ruang Tanjong, Anggrek dan Dahlia di Rumah Sakit Jiwa Pemerintah Aceh. Penelitian telah dilaksanakan pada tanggal 4 sampai dengan 7 Desember 2018. Penentuan jumlah sampel dalam penelitian ini dilakukan dengan menggunakan teknik total sampling yaitu seluruh populasi akan dijadikan sampel dalam penelitian yaitu sebanyak 41 orang. Uji coba instrumen berupa uji validitas dan uji reliabilitas, hasil uji instrumen untuk menilai validitas dan reliabilitas pertanyaan pada 
kuesioner yang digunakan sebagai alat pengukuran data dengan menggunakan sistem aplikasi komputerisasi SPSS.

\section{HASIL DAN PEMBAHASAN}

Hubungan pengetahuan spritualitas pasien dengan penerapan spritualitas hubungan antara variabel pengetahuan dengan variabel penerapan spritualitas, dapat dilihat pada tabel berikut ini:

Tabel 1. Hubungan Pengetahuan Spritual dengan Penerapan Spiritual di Rumah Sakit Jiwa Pemerintah Aceh Tahun 2018

\begin{tabular}{|c|c|c|c|c|c|c|c|c|}
\hline \multirow[b]{2}{*}{ No. } & \multirow[b]{2}{*}{$\begin{array}{c}\text { Pengetahuan } \\
\text { Spritualitas }\end{array}$} & \multicolumn{4}{|c|}{ Penerapan Spiritualitas } & \multirow[b]{2}{*}{ Total } & \multirow[b]{2}{*}{$\%$} & \multirow[b]{2}{*}{ p-Value } \\
\hline & & Baik & $\%$ & $\begin{array}{c}\text { Kurang } \\
\text { baik }\end{array}$ & $\%$ & & & \\
\hline 1. & Baik & 7 & 17,1 & 8 & 19,5 & 15 & 36,6 & \multirow{3}{*}{0,03} \\
\hline 2. & Kurang baik & 4 & 9,8 & 22 & 53,7 & 26 & 63,4 & \\
\hline & Jumlah & 11 & 26,8 & 30 & 73,2 & 41 & 100,0 & \\
\hline
\end{tabular}

Berdasarkan Tabel 1 diatas menunjukkan bahwa pengetahuan spritualitas pasien dipengaruhi dari kurang baiknya penerapan spritualitas yaitu 22 responden (53,7\%).

Hubungan antara variabel sikap dengan variabel penerapan spritualitas, dapat dilihat pada tabel berikut ini:

Tabel 2. Hubungan Sikap Spriritual dengan Penerapan Spriritual di Rumah Sakit Jiwa Pemerintah Aceh Tahun 2018

\begin{tabular}{|c|c|c|c|c|c|c|c|c|}
\hline \multirow[b]{2}{*}{ No. } & \multirow[b]{2}{*}{ Sikap Spritual } & \multicolumn{4}{|c|}{ Penerapan Spiritualitas } & \multirow[b]{2}{*}{ Total } & \multirow[b]{2}{*}{$\%$} & \multirow[b]{2}{*}{ p-Value } \\
\hline & & Baik & $\%$ & $\begin{array}{c}\text { Kurang } \\
\text { baik }\end{array}$ & $\%$ & & & \\
\hline 1. & Positif & 3 & 7,3 & 14 & 34,1 & 17 & 41,5 & \multirow{3}{*}{0,22} \\
\hline 2. & Negatif & 8 & 19,5 & 16 & 39,0 & 24 & 58,5 & \\
\hline & Jumlah & 11 & 26,8 & 30 & 73,2 & 41 & $\mathbf{1 0 0 , 0}$ & \\
\hline
\end{tabular}

Berdasarkan Tabel 2, menunjukkan bahwa sikap spritualitas pasien negatif dipengaruhi dari kurang baiknya penerapan spritualitas yaitu 16 responden (39\%). 
Tabel 3. Hubungan Tindakan Spritual dengan Penerapan Spiritual di Rumah Sakit Jiwa Pemerintah Aceh Tahun 2018

\begin{tabular}{|c|c|c|c|c|c|c|c|c|}
\hline \multirow[b]{2}{*}{ No. } & \multirow[b]{2}{*}{ Tindakan Spritual } & \multicolumn{4}{|c|}{ Penerapan Spiritualitas } & \multirow[b]{2}{*}{ Total } & \multirow[b]{2}{*}{$\%$} & \multirow[b]{2}{*}{ p-Value } \\
\hline & & Baik & $\%$ & $\begin{array}{c}\text { Kurang } \\
\text { baik }\end{array}$ & $\%$ & & & \\
\hline 1. & Baik & 7 & 17,1 & 7 & 17,1 & 14 & 34,1 & \multirow{3}{*}{0,02} \\
\hline 2. & Kurang baik & 4 & 9,8 & 23 & 56,9 & 27 & 65,9 & \\
\hline & Jumlah & 11 & 26,8 & 30 & 73,2 & 41 & 100,0 & \\
\hline
\end{tabular}

Berdasarkan Tabel 3, menunjukkan bahwa tindakan spritualitas pasien kurang baik dipengaruhi dari kurang baiknya penerapan spritualitas yaitu 23 responden $(56,1 \%)$.

\section{Pembahasan}

1. Hubungan Pengetahuan Spritual Pasien dengan Penerapan Spriritual

Dari hasil Uji statistik diketahui $p$ value 0,03 menunjukkan $<\alpha 0,05$, yang berarti ada hubungan pengetahuan spritualitas dengan penerapan spiritualitas terhadap perilaku spiritual pasien gangguan jiwa pada Rumah Sakit Jiwa Pemerintah Aceh Tahun 2018. Hal ini sesuai dengan pendapat (Rahman, 2009). Spiritualitas dapat mempengaruhi proses penyembuhan dan penguatan diri atau koping pada pasien dalam menghadapi penyakitnya dan pendapat (Young, C \& Koopsen, C, 2007). Pendekatan sistematis terhadap perawatan spiritual pasien menjamin perawatan yang tepat dan efektif.

2. Hubungan Sikap Spritualitas Pasien dengan Penerapan Spritualitas

Dari hasil Uji statistik diketahui $p$ value 0,22 menunjukkan $>\alpha 0,05$ maka yaitu tidak ada hubungan antara sikap spritualitas pasien dengan penerapan spritualitasdengan penerapan spiritual terhadap perilaku spiritual pasien gangguan jiwa pada Rumah Sakit Jiwa Pemerintah Aceh Tahun 2018. Hal ini sesuai dengan pendapat (Anhorida, 2016) bahwa kehadiran perawat selalu memberikan ketenangan bagi pasien. Rasa intuitif perawat yang demikian didefinisikan sebagai pendampingan. Ada empat cara pendampingan pada pasien menurut Osterman dan Schwart-Barcott; presensi (presence) yaitu ketika perawat hadir secara fisik tetapi tidak fokus pada pasien; presensi parsial (Partial prescense) yaitu ketika perawat hadir secara fisik dan mulai berusaha fokus pada pasien; presensi penuh (Full prescense) yaitu ketika perawat hadir disamping pasien baik secara fisik, mental, maupun emosional, dan secara sengaja memfokuskan diri pada pasien; presensi transenden 
(Transcendent prescense) yaitu ketika perawat hadir disamping pasien baik secara fisik, mental, emosional, maupun spiritual.

3. Hubungan Tindakan Spritualitas Pasien dengan Penerapan Spritualitas

Hasil Uji statistik diketahui $p$ value 0,02 menunjukkan $<\alpha 0,05$, yaitu ada hubungan antara tindakan spritualitas pasien dengan penerapan spritualitas.dengan penerapan spiritual terhadap perilaku spiritual pasien gangguan jiwa pada Rumah Sakit Jiwa Pemerintah Aceh Tahun 2018. Hal ini sesuai dengan pendapat (Izzan, A, 2010). Pada tahap implementasi diperlukan tindakan-tindakan keperawatan untuk membantu pasien memenuhi kebutuhan spiritual antara lain meliputi kehadiran atau pendampingan, dukungan praktik keagamaan, membantu pasien berdo'a atau mendo'akan, dan merujuk pasien untuk konseling spiritual. Menurut teori kelliat, jenis terapi bimbingan spiritual dibagi menjadi empat, yaitu dzikir, sholat, membaca do'a dan membaca shalawat. Dari empat jenis terapi bimbingan spiritual diatas yang paling relevan dilakukan pada individu dengan gangguan konsep harga diri rendah adalah terapi bimbingan spiritua terstruktur.

\section{KESIMPULAN}

Berdasarkan hasil penelitian yang telah dilakukan, maka dapat disimpulkan sebagai berikut:

1. Terdapat hubungan pengetahuan spritualitas pasien dengan penerapan spritualitas yaitu $\mathrm{p}$ Value $0,03$.

2. Tidak terdapat hubungan sikap spritualitas pasien dengan penerapan spritualitas yaitu $\mathrm{p}$ Value 0,22

3. Terdapat hubungan tindakan spritualitas pasien dengan penerapan spritualitas yaitu $\mathrm{p}$ Value 0,02

\section{SARAN}

Berdasarkan kesimpulan dari hasil penelitian, maka dalam upaya meningkatkan mutu pelayanan kesehatan jiwa dalam upaya penerapan spritualitas pada pasien khususnya di ruang Tanjong, ruang Anggrek dan ruang Dahlia, maka peneliti memberikan saran sebagai berikut:Bagi Perawat di Rumah Sakit Jiwa Pemirntah Aceh diharapkan kepada tenaga kesehatan untuk meningkatkan lagi penerapan spritualitas pada pasien sehingga pasien 
mendapatkan spritulitas yang dapat mengembalikan semangat untuk kesembuhan. Bagi Penelitian Lanjutan hasil penelitian ini dapat dijadikan data awal untuk mengembangkan penelitian berikutnya tentang penerapan spritualitas khususnya pada pasien gangguan kejiwaan di Rumah Sakit Jiwa Pemerintah Aceh.

\section{DAFTAR PUSTAKA}

Anhorida. (2016). Asuhan Keperawatan Bimbingan Spiritual Pada Klien Gangguan Jiwaharga Diri Rendah di RSJ DR. Radjiman Wediodiningrat Lawang-Malang.

Carpenito, L.J. (2001). Buku Saku Diagnosa Keperawatan. Edisi 8. Jakarta: Penerbit Buku Kedokteran EGC.

Depkes, R.I.(2009). Undang-Undang No.36 Tentang Kesehatan. Jakarta.

Hamid, A. Yani. (2014). Buku Ajar Spiritual Dalam Keperawatan, Jakarta: Widya Medika.

Ilhamsyah.(2010). Hubungan Pelaksanaan Keperawatan Spiritual Terhadap Kepeuasan Spiritual Pasien di Rumah SakitIbnu Sina Makasar, Fakultas Kedokteran, Manajemen Ilmu Keperawatan Universitas Hasanudin, Makasar.

Izzan, A. (2010). Sakitku Ibadahku; Panduan Ibadah bagi pasien, keluarga pasien, dokter, dan perawat; agar sakit selalu bernilai ibadah. Jakarta: Klinikal Mahira, Jakarta.

Nanda International. (2011). Diagnosis Keperawatan; Definisi dan klasifikasi. Alih Bahasa; Made Saraswati, Dwi widiarti, dan Estu Tiar. Jakarta: Penerbit Buku Kedokteran EGC.

Rohman. (2009). Faktor-faktor yang berhubungan dengan pemberian asuhan spiritual oleh perawat di RS Islam Jakrta. Tesis Fakultas Ilmu Keperawatan Universitas Indonesia (FIK. UI). Tidak dipublikasikan.

Young, C \& Koopsen, C. (2007). Spiritualitas, Kesehatan, dan Penyembuhan. Medan; Bina Media Perintis, Medan. 